\title{
Cardiovascular disease in pregnancy
}

\author{
Rupa Vyas, Priya Gupta*, Sapana Shah, Komal Rangoliya
}

Department of Obstetrics and Gynecology, Smt N.H.L. Municipal Medical College, Sheth V.S. General Hospital, Ahmedabad, Gujarat, India

Received: 06 January 2019

Revised: 02 August 2019

Accepted: 08 August 2019

\section{*Correspondence:}

Dr. Priya Gupta,

E-mail: priyagupta245@gmail.com

Copyright: $@$ the author(s), publisher and licensee Medip Academy. This is an open-access article distributed under the terms of the Creative Commons Attribution Non-Commercial License, which permits unrestricted non-commercial use, distribution, and reproduction in any medium, provided the original work is properly cited.

\section{ABSTRACT}

Background: Maternal cardiac disease is a major cause of non-obstetric maternal morbidity and mortality. The care of pregnant women with cardiac disease requires a multidisciplinary approach, involving obstetricians, cardiologists and anesthesiologist.

Methods: A prospective analytical study of maternal heart disease and its fetomaternal outcome is carried out in the department of obstetrics and gynecology at tertiary hospital and teaching institute. The study was carried out on 50 cases belonging to age group 18-50 years with various cardiac diseases during their pregnancy and peripartum period.

Results: In this study, $78 \%$ of the cases were registered with our hospital. The present study shows about $32 \%$ of the women having cardiac disease were in the age group of 20-25 years. $34 \%$ belonged to NYHA class II and had a relatively uneventful peripartum period. Among all forms of heart disease, RHD was common constituting $26 \%$ of cases. Most common condition associated with cardiac disease in pregnancy was preeclampsia (36\%) in our study, with anemia being other one (10\%). The common complications were congestive cardiac failure $(12 \%)$ and pulmonary edema (8\%). Combination of diuretics and beta blockers was used most commonly (22\%). 56\% of women delivered with caesarean section. 42 patients delivered after age of viability with $29(69 \%)$ term deliveries and 13 (30\%) preterm deliveries with 8 requiring NICU care.

Conclusions: Valvular heart disease of rheumatic origin is the most common cardiac disease associated with pregnancy.The availability of adequate systems of early diagnosis of cardiac lesion, reference to tertiary care center $\&$ close monitoring of patient and delivery with multidisciplinary approach include specialized cardiologic care, high risk obstetric support and neonatology expertise that can minimize the serious consequences and helps to improve fetomaternal outcome. Pre-conceptional counseling and surgical correction of certain conditions improves maternal as well as fetal outcome. Awareness needs to be created about heart diseases during pregnancy and the importance of regular antenatal check-ups.

Keywords: ASD, CHD, IUCD, RHD, PPH, MS, MR, VSD

\section{INTRODUCTION}

An increased prevalence of cardiovascular disease has been found in women of childbearing age nowadays due to increase in detection rate with easy availability of better diagnostic procedures. Progress in medical and surgical treatment has resulted in larger number of women with heart disease surviving to child-bearing years and proceeding with pregnancy. Although cardiac disease complicates a small percentage (1-4\%) of all pregnancies, maternal cardiac disease is a major cause of non-obstetric maternal morbidity and mortality. Profound hemodynamic changes during pregnancy have the potential to adversely affect maternal and fetal health, 
especially in the presence of underlying heart diseases. Rise in heart rate, stroke volume, and cardiac output can result in cardiac de-compensation in women with heart disease. Up to $4 \%$ of pregnancies may have cardiovascular complications despite no known prior disease. The care of pregnant women with cardiac disease requires a multidisciplinary approach, involving obstetricians, cardiologists and anesthesiologist. In the past, rheumatic heart disease was the most common form of cardiac diseases and is still predominant in developing countries. Study by Nqayana $\mathrm{T}$ et al showed $81 \%$ incidence of RHD which was conducted in Africa. ${ }^{1}$ Asghar $\mathrm{F}$ et al study states that $48 \%$ of cases were belonging to valvular heart disease, with $30 \%$ women had rheumatic etiology. ${ }^{2}$ Kealey A et al, states that with the increasing age and fertility of mothers, the incidence of coronary artery disease is likely to increase. ${ }^{3}$ In developing countries, incidence of rheumatic heart disease is still high as compared to developed countries where incidence of congenital disease is higher than RHD. Patel A et al, states that fetal mortality rate remains high $(33 \%)$ in cases of concomitant heart disease. Davies GAL et al, states that most patients with aortic regurgitation of rheumatic origin have associated mitral valve disease and their clinical course is probably determined more by the extent of their mitral valve disease than by their aortic regurgitation. ${ }^{5}$ Congenital heart disease is also commonly seen now because advances in the early diagnosis (even prenatal) and treatment of congenital heart disease have made it possible for affected children to reach adulthood and attempt pregnancy. Objectives of the study are to find the prevalence and causes of maternal heart disease, their early detection and appropriate treatment for achieving best fetomaternal outcome.

\section{METHODS}

A total of 21577 women delivered in our institute during September 2015 to December 2017. Out of these women, a prospective analytical study was carried out on 50 cases with various cardiac diseases during their pregnancy. Patients with cardiac diseases were studied throughout their pregnancy and peripartum period.

\section{Inclusion criteria}

- Patients coming to LR and OPD, patients belonging to age group 18-50 years, patients with previous history of heart disease, patients newly diagnosed with heart disease.

\section{RESULTS}

Present study $0.23 \%$ incidence of cardiac disease in pregnant women.

The present study shows about $32 \%$ of the women having cardiac disease were in the age group of 20-25 years.
Table 1: Incidence of cardiac disease in pregnancy.

\begin{tabular}{|ll|}
\hline Study & Incidence $(\%)$ \\
\hline Present study & 0.23 \\
\hline
\end{tabular}

Table 2: Demographic data.

\begin{tabular}{|ll|}
\hline $\begin{array}{l}\text { Maternal age } \\
\text { (years) }\end{array}$ & $\begin{array}{l}\text { Present study total=50 cases } \\
(\%)\end{array}$ \\
\hline$<20$ & $3(6)$ \\
\hline $20-25$ & $16(32)$ \\
\hline $26-35$ & $22(44)$ \\
\hline$>35$ & $4(8)$ \\
\hline
\end{tabular}

Table 3: Registered vs. emergency cases.

\begin{tabular}{|lll} 
Total no of cases & Registered & Unregistered \\
\hline $\mathbf{5 0}$ & $39(78 \%)$ & $11(22 \%)$ \\
\hline
\end{tabular}

Table 4: New York heart association (NYHA) grade of heart disease and pregnancy.

\begin{tabular}{|ll|}
\hline NYHA Class & Present study total $=50$ cases $(\%)$ \\
\hline Grade II & $17(34)$ \\
\hline Grade III & $5(10)$ \\
\hline Grade IV & $3(6)$ \\
\hline
\end{tabular}

In present study, $78 \%$ of the cases were registered in the antenatal OPD at our hospital and $22 \%$ of the total cases were unregistered.

The present study shows $34 \%$ of the cases belonging to NYHA class II at first antenatal visit. Patients of class III or IV were $10 \%$ and $6 \%$ respectively.

In present study, 48 cases were valvular heart disease, out of which $26 \%$ belonged to Rheumatic heart disease.

In present study, there were total 13 cases of RHD, out of which mitral stenosis and mitral regurgitation were most prevalent (30.8\% each).

Table 5: Clinical spectrum of cardiac disease.

\begin{tabular}{|l|l|}
\hline A etiology & $\begin{array}{l}\text { Present study } \\
\text { total=50 cases (\%) }\end{array}$ \\
\hline $\begin{array}{l}\text { Rheumatic valvular heart } \\
\text { disease (RHD) }\end{array}$ & $13(26)$ \\
\hline Congenital heart disease (CHD) & $9(18)$ \\
\hline Other valvular heart disease & $11(22)$ \\
\hline Cardiomyopathy & $5(10)$ \\
\hline Ischemic heart disease & $2(4)$ \\
\hline Congestive heart failure & $3(6)$ \\
\hline Pulmonary artery hypertension & $6(12)$ \\
\hline Others & - \\
\hline
\end{tabular}


Present study had total 9 patients of congenital heart disease out of which ASD was most common (66.7\%).

Table 6: Lesions of RHD.

\begin{tabular}{|ll|}
\hline Type of lesions & $\begin{array}{l}\text { Present study total=13 } \\
\text { cases }(\%)\end{array}$ \\
\hline Mitral stenosis (MS) & $4(30.8)$ \\
\hline MS + MR & $2(15.3)$ \\
\hline Mitral regurgitation (MR) & $4(30.8)$ \\
\hline Aortic regurgitation (AR) & - \\
\hline Aortic stenosis (AS) & - \\
\hline Metallic valve & $3(23.1)$ \\
\hline
\end{tabular}

Table 7: Types of congenital lesion.

\begin{tabular}{|ll|}
\hline Type of lesion & $\begin{array}{l}\text { Present study } \\
\text { total=9 cases }(\%)\end{array}$ \\
\hline Atrial septal defect & $6(66.7)$ \\
\hline Ventricular septal defect & $2(22.2)$ \\
\hline Coarctation of aorta & $1(11.1)$ \\
\hline Patent ductus arteriosus & - \\
\hline Tetralogy of fallot & - \\
\hline
\end{tabular}

In present study, combination of diuretics and beta blockers is used most commonly (22\%). Beta blocker drug prescribed was Tab Metoprolol.

Table 8: Medical treatment for cardiac disease.

\begin{tabular}{|ll|}
\hline Medical treatment & $\begin{array}{l}\text { No. of cases and } \\
\text { percentage }(\%)\end{array}$ \\
\hline Diuretics & $7(14)$ \\
\hline Diuretics + Digoxin & $3(6)$ \\
\hline Diuretics + Beta blockers & $11(22)$ \\
\hline Beta blockers & $5(10)$ \\
\hline Inj Benzathine penicillin & $7(14)$ \\
\hline Anticoagulants & $4(8)$ \\
\hline
\end{tabular}

Congestive heart failure and pulmonary edema were most common complications seen in present study (12\% and $8 \%$ respectively).

Most common conditions associated with cardiac disease in pregnancy in our study were preeclampsia $(36 \%)$ and anemia (10\%).

Out of 50 cases, 28 cases underwent caesarean section and 22 cases had vaginal delivery.

42 patients were delivered after the age of viability with $29(69 \%)$ term deliveries and 13 (30\%) preterm deliveries, with 8 requiring NICU care. 4 patients had intra uterine death complicating their pregnancy. The rate of preterm birth is $30 \%$ in our study. 4 women $(9.5 \%)$ had intrauterine death in our study and 34 new born (9.5\%) had Apgar $<5$ at 5 minutes. The incidence of IUGR and NICU admission is $16.6 \%$ and $21.4 \%$ respectively. Out of the 9 NICU admissions, 8 babies recovered successfully and were discharged and 1 baby expired due to RDS.

Table 9: Complications associated with cardiac disease in pregnancy.

\begin{tabular}{|ll|}
\hline Outcome & $\begin{array}{l}\text { Present study } \\
\text { total=50 cases (\%) }\end{array}$ \\
\hline Congestive heart failure (CHF) & $6(12)$ \\
\hline Pulmonary edema & $4(8)$ \\
\hline $\begin{array}{l}\text { Rhythm disorders (AF-atrial } \\
\text { fibrillation) }\end{array}$ & $2(4)$ \\
\hline Syncopal attack & - \\
\hline Hyper coagulation & - \\
\hline Death & $2(4)$ \\
\hline $\begin{array}{l}\text { Non-cardiac complications } \\
\text { PPH Wound gap }\end{array}$ & - \\
Puerperal sepsis & $1(2)$ \\
\hline
\end{tabular}

Table 10: Associated conditions.

\begin{tabular}{|ll|}
\hline Condition & $\begin{array}{l}\text { Present study total= } \\
50 \text { cases }(\%)\end{array}$ \\
\hline Anemia & $5(10)$ \\
\hline Preeclampsia & $18(36)$ \\
\hline Eclampsia & $4(8.0)$ \\
\hline Thrombocytopenia & $3(6.0 \%)$ \\
\hline Epilepsy & $2(4.0)$ \\
\hline Asthma & - \\
\hline Diabetes mellitus & - \\
\hline
\end{tabular}

Table 11: Outcome of pregnancy.

\begin{tabular}{|ll|}
\hline Mode & $\begin{array}{l}\text { Present study total }=50 \\
\text { cases }(\%)\end{array}$ \\
\hline Caesarean section & $28(56)$ \\
\hline Preterm CS & $7(14)$ \\
\hline Term CS & $21(42)$ \\
\hline Vaginal delivery & $22(44)$ \\
\hline Preterm ND & $8(16)$ \\
\hline Term ND & $14(28)$ \\
\hline Forceps/vacuum & 0 \\
\hline
\end{tabular}

Table 12: Fetal outcome.

\begin{tabular}{|l|l|}
\hline \multicolumn{1}{|c|}{} & $\begin{array}{l}\text { Present study total=42 } \\
\text { cases (after the age of } \\
\text { viability) }(\%)\end{array}$ \\
\hline Term delivery & $29(69)$ \\
\hline Preterm & $13(30)$ \\
\hline IUD & $4(9.5)$ \\
\hline Apgar $<5$ at 5 minutes & $4(9.5)$ \\
\hline NICU Admissions & $9(21.4)$ \\
\hline IUGR & $7(16.6)$ \\
\hline
\end{tabular}


In present study, a majority of the women (48\%) chose barrier method as contraception after the approach of counseling.

Table 13: Contraception.

\begin{tabular}{|ll|}
\hline Methods & No. of cases and percentage (\%) \\
\hline DMPA & $4(8)$ \\
\hline Barrier & $24(48)$ \\
\hline Tubal ligation & $2(4)$ \\
\hline IUCD & $1(2)$ \\
\hline None & $14(28)$ \\
\hline
\end{tabular}

\section{DISCUSSION}

This study was conducted at our hospital on 50 on pregnant women with heart disease between the age group of 18 to 50 years for 30 months. The study (Table 1) shows $0.23 \%$ incidence of cardiac disease in pregnant women. The present study (Table 2) shows about $32 \%$ of the women having cardiac disease were in the age group of 20-25 years. $44 \%$ of the women belonged to their late twenties and early thirties (26-35 years). $6 \%$ cases belonged to teenage pregnancy and $8 \%$ cases belonged to elderly age group (>35 years).

In present study (Table 3), $78 \%$ of the cases were registered in the antenatal OPD at our hospital and were under the combined care of obstetrician and cardiologists, $22 \%$ of the total cases were unregistered. Out of the total unregistered cases, 6 women $(12 \%)$ had not visited any medical centre prior to the visit here and 5 women $(10 \%)$ were registered at private hospitals. Maternal morbidity and mortality increase in unregistered cases who have not taken any treatment. In our study (Table 4), 34\% belonged to NYHA class II and had a relatively uneventful peripartum period. This was comparable to study by Nqayana et al T, in which NYHA class II cases were $34.7 \% .^{1}$ Patients of class III $(10 \%)$ and IV $(6 \%)$ were admitted immediately and required close monitoring for good maternal and perinatal outcome. In present study (Table 5), out of all forms of heart disease prevalent, those of valvular origin $(48 \%)$ were common, with RHD constituting $26 \%$ of cases. This was comparable to Farhana et al, in which $48 \%$ of cases were belonging to valvular heart disease with $30 \%$ women had rheumatic etiology. ${ }^{2}$ Congenital heart disease patients were $18 \%$ cases, pulmonary artery hypertension were $13.3 \%$ and that of IHD were $4.4 \% .^{5}$ Cases of cardiomyopathy were present.

Kealey A et al, states that with the increasing age and fertility of mothers, the incidence of coronary artery disease is likely to increase. ${ }^{3}$ Anish Patel A et al, states that fetal mortality rate remains high $(33 \%)$ in cases of concomitant heart disease. ${ }^{4}$ Davies GAL et al states that most patients with aortic regurgitation of rheumatic origin have associated mitral valve disease and their clinical course is probably determined more by the extent of their mitral valve disease than by their aortic regurgitation. ${ }^{5}$

In present study (Table 6), there were total 13 cases of RHD, out of which mitral stenosis and mitral regurgitation were most prevalent (30.8\% each). Our study shows $15.3 \%$ cases of MS + MR. Present study (Table 7) had total 9 patients of congenital heart disease out of which ASD was most common $(66.7 \%)$. In present study (Table 8) combination of diuretics and beta blockers is used most commonly $(22 \%)$. Beta blocker drug prescribed was Tab Metoprolol. 3 patients $(6 \%)$ were taking Diuretics + Digoxin. 7 patients $(15.6 \%)$ were only on diuretic treatment. 4 patients were on anticoagulant treatment, 3 were taking Tab Warfarin and had history of metallic valve and 1 patient was on Tab Clopidogrel (anticoagulant) and had history of anterior wall MI. 7 women with RHD were taking Inj Benzathine Penicillin prophylactically to prevent subacute bacterial endocarditis (SABE).

In present study (Table 9) congestive heart failure and pulmonary edema were most common complications seen (12\% and $8 \%$ respectively). 2 women (4\%) developed atrial fibrillation during pregnancy. There was wound gap in 1 of our patient. Maternal mortality was $4 \%$, cause of death in both patients were congestive cardiac failure, both the mortality occurred in postpartum period. In our study (Table 10), most common condition associated with cardiac disease in pregnancy were preeclampsia (36\%) and anemia (10\%). Eclampsia and thrombyocytopenia were $8 \%$ and $6 \%$ of cases respectively in our study.

In our study (Table 11), majority of the cases were delivered by caesarean section (56\%). CS was opted mainly in the case of obstetric indications. Preterm and term CS were $14 \%$ and $42 \%$ respectively. 22 cases (44\%) underwent vaginal delivery including 8 cases of preterm and 14 cases of term vaginal deliveries, which is compared to the study by Soma Pillay et al 20086 who recorded rate of vaginal delivery was $43.6 \%$. The study by Patil $\mathrm{V}$ et al, showed higher rate of vaginal delivery $(53.3 \%)$ in cardiac patients, which is against our study. ${ }^{7}$

In our study (Table 12), 42 patients delivered after age of viability with $29(69 \%)$ term deliveries and $13(30 \%)$ preterm deliveries. Doshi et al have reported similar incidence of preterm births $(29.2 \%)$ as compared to our study. ${ }^{8} 4$ patients had intra uterine death complicating their pregnancy. The rate of preterm birth is $30 \%$ in our study. 4women $(9.5 \%)$ had intrauterine death in our study and 34 new born $(9.5 \%)$ had Apgar $<5$ at 5 minutes. The incidence of IUGR and NICU admission are $16.6 \%$ and $21.4 \%$ respectively, which corresponds to study by Doshi et al, which are $18.8 \%$ and $25 \%$ respectively. ${ }^{8}$ Out of the 9 NICU admissions, 8 babies recovered successfully and were discharged and 1 baby expired due to RDS.

In present study (Table 13), a majority of the cases (48\%) chose barrier method as contraception after the approach 
of counseling, 4 cases (8\%) preferred Inj DMPA, and 2 cases $(4 \%)$ underwent tubal ligation and 1 case preferred IUCD. However, 28\% did not choose any method of contraception.

\section{CONCLUSION}

The outcome of this study reiterates the fact that maternal heart disease is still an important challenge for obstetricians. Valvular heart disease of rheumatic origin is the most common cardiac disease associated with pregnancy. The availability of adequate systems of early diagnosis of cardiac lesion, reference to tertiary care centre, timely admission and close monitoring of patient and delivery with multidisciplinary approach include specialized cardiologic care, high risk obstetric support and neonatology expertise that can minimize the serious consequences of poorly controlled heart disease in pregnancy and helps to improve fetomaternal outcome. Women with cardiac conditions who desire or anticipate pregnancy should be offered pre-conceptional counseling regarding effect of pregnancy on cardiac condition, effect of cardiac condition on pregnancy, the neonatal/perinatal risks and ways to optimize their cardiac condition before pregnancy occurs. It is important to classify the disease at each antenatal visit. NYHA class I or II patients may worsen during the course of pregnancy.

Surgical correction of certain conditions before attempting pregnancy improves maternal as well as fetal outcome. Contraceptive advice to avoid unwanted pregnancy is essential part of counseling. Discussions pertaining to contraception options should begin early and may need to be reassessed as women age or if there are changes in maternal health. Awareness needs to be created in general population about heart disease, the risks associated with it during pregnancy and the importance of regular antenatal check-ups.

\section{Recommendations}

The early diagnosis of cardiac lesion, reference to tertiary care centre, timely admission and close monitoring of patient and delivery with multidisciplinary approach helps to improve fetomaternal outcome. It can have a drastic positive effect on the fetomaternal outcome.

Funding: No funding sources

Conflict of interest: None declared

Ethical approval: Not required

\section{REFERENCES}

1. Nqayana Nqayana T, Moodley J, Naidoo DP. Cardiac disease in pregnancy. Cardio $\mathbf{J}$ Africa. 2008;19(3):145.

2. Asghar F, Kokab H. Evaluation and outcome of pregnancy complicated by heart disease. JPMA. 2005;55:416.

3. Kealey AJ. Coronary artery disease and myocardial infarction in pregnancy: a review of epidemiology, diagnosis, medical and surgical management. Can J Cardiol. 2010;26(6):185-9.

4. Patel A, Asopa S, Tang AT, Ohri SK. Cardiac surgeryduring pregnancy. Texas Heart Institute J. 2008;35(3):307.

5. Davies GA, Herbert WN. Acquired heart disease in pregnancy. J Obstetrics Gynaecol Canada. 2007;29(6):507-9.

6. Soma-Pillay P, Macdonald AP, Mathivha T, Bakker J, Mackintoch M. Cardiac disease in pregnancy-a four-year audit at pretoria academic hospital (20022005). South African Med J. 2008;98(7):553-6.

7. Patil V, Bhingare P, Murthy B. Evaluation of maternal and foetal outcome of pregnancy with heart disease with special reference to surgically corrected heart diseases. Int J Sci Res Pub. 2014;184.

8. Doshi HU, Oza HV, Tekani H, Modi K. Cardiac disease in pregnancy-maternal and perinatal outcome. J Indian Med Asso. 2010;108(5):278-80.

Cite this article as: Vyas R, Gupta P, Shah S, Rangoliya K. Cardiovascular disease in pregnancy. Int J Reprod Contracept Obstet Gynecol 2019;8:3789-93. 